\title{
Strategic Planning and Change Management in Telecommunication Industry in Kenya: Case Study of Telkom Kenya
}

\author{
Dr. Washington Okeyo, Ph.D \\ Vice-Chancellor, \\ Management University of Africa \\ Divinah Rachel Nyaera \\ Master of Management and Leadership, \\ Management University of Africa
}

\begin{abstract}
The purpose of the study was to examine the effect of strategic planning on change management in the telecommunication industry with the specific reference to Telkom Kenya Ltd. The study was anchored on Contingency Planning Theory. The target population was 1450 employees of Telkom Kenya. Stratified proportional sampling was used to get a suitable sample of 145 respondents and the study adopted a descriptive research design. Questionnaires were the main data collection tool and they were pilot tested on 15 staff at Telkom Thika branch before being administered to the target audience. Analysis of data was done using Statistical Package for Social Sciences Version 24. Descriptive statistics, specifically, means, averages and percentages were used to analyse individual variables. Simple tabulations were used to presented descriptive statistics. This study also used inferential statistics to examine the relationship between the study variables. Data was analysed using quantitative methods through regression analysis and presentation of data was in form of tables and figures. The study established that strategic planning had significant effect on change management. Specifically, the findings indicate that strategic planning and change management are positively and significantly related $\left(R^{2}=0.57, p \leq 0.000\right)$. This study concluded that strategic planning plays an important role in change management such that change in the strategic planning results in positive variation in change management. The study recommended that, Telkom Kenya should treat strategic planning in the organization as one of the critical survival factors when implementing changes.
\end{abstract}

Key Words: Strategic Planning, Change Management, Telecommunication Industry, Telkom Kenya.

\section{Background}

\section{INTRODUCTION}

Change management remains a key determinant of whether or not a company will survive and prosper in an ever-evolving economic ecosystem. The main goal of change management is to successfully implement new processes, products and business strategies while minimizing negative outcomes (Hameri \& Hintsa, 2014). The change process itself has many different dynamics including spiritual aspects, such as focusing on core values or empowering the employees, which are critical for organizational learning and long-term sustainability (Burnes \& Jackson, 2011). Organizations too are complex self-generating systems with many interrelational dynamics and so, transformation cannot be wholly controlled and may lead to unpredicted outcomes. 
According to Higgs and Rowland (2010) most organizations initiate change with a particular objective in mind. The goals of change management have a typical economic angle that includes cost reduction, improved organizational performance, and increased profits (Nel \& Beudeker, 2015). Burnes and Jackson (2011) argue that it is important to first evaluate why the organization is seeking change. Management of change process is the systematic approach and application of knowledge, resources and tools in order to deal with change management. This involves defining and adopting organizational strategies, technologies as well as procedure to handle changes in the external conditions and the operating business environment.

In the United States of American a study by Joshi and Jha (2017) examined if middle level managers have any preference on the implementation style when implementing strategic changes. Their analysis reflected that when middle level managers sense that the organization's survival is at stake, they are likely to choose an authoritative style. The study further established, among other things, that middle level managers focus their emotions when it comes to implementing strategic changes and that the role played by these managers is critical for organizational survival (Joshi \& Jha, 2017).

Ansoff and Nakamura, (2013) opine that strategic planning involves, identifying the firm's mission and objectives, developing long term objectives and short-term operational plans, plan preparation, application and actual evaluation and control of the implementation process. The practices of strategic planning influence the organizational performance through improving asset growth, sales revenue volume, competitive advantage, gain market share and enhance profitability and productivity of the organizations. No organization can elude the confrontation of change. Therefore, effective strategic planning is vital to redressing spasmodic business environment while sustaining the firm's competitive position in the marketplace Ansoff and Nakamura, (2013).

\section{Strategic planning}

Strategic planning is a crucial part for implementing strategy. Strategic planning can't be directionless because it's defined by its purpose; in most of these cases is the realization of the overall organizational objective. Strategic planning is inseparably linked with strategic intentions. Companies that put more focus on strategy implementation will definitely have happier employees, satisfied customers and improved profits Beaudan, (2012). It is therefore manifest that the key to challenges that organizations face today is strategic management. Strategic management is influenced by many factors such as communicating the process, implementing the systems, the people who communicate the process, and the instruments already put in place for control and co-ordination Mintzberg, Lample, Quinn, and Ghoshal, (2002). According Odundo (2015) there are eight elements of strategic planning which include planning to plan, mission, goals and values, needs assessment, strategic objective, outcome measures, strategic priorities, strategies and lastly performance feed forward.

\section{Change Management}

Change management is the effective management of a business change process such that Executive leaders, managers and front-line employees work in concert to successfully implement the needed process, technology or way of doing business. It is estimated that 70 percent of change programs fail to achieve their goals, largely due to employee resistance and lack of management support. The goal of change management is to implement these business changes quickly in an attempt to improve organizational performance while minimizing the impact on productivity, avoiding unnecessary turnover or loss of valued employees, 
eliminating any adverse impact on their customers and achieving the desired business outcomes as soon as possible (Burnes \& Jackson, 2011).

The characteristics of change management are mainly categorized along the following two dimensions; radical versus incremental change and reactive versus proactive change. Radical changes is defined as changes that have an impact on the whole system of the organization and fundamentally redefine what the organization is or change its basic framework, including strategy, structure, people, processes, and (in some cases) core values (Nadler \& Tushman, 2013).

\section{Telkom Kenya Limited}

Telkom Kenya was established in 1999 as telecommunications service provider by the Companies Act. The organization is responsible for providing integrated communications solution in Kenya with a range of voice and data services as well as network facilities. As at June 2017, the organization had a customer base of 2.8 million. This number had increased steadily in the past months due to the rebranding and intensive marketing. The customer base at the time of this study stood at 4.8 million in the last quarter of 2018.

The company has over the years, undergone various transformations. Ongoing infrastructural developments by operators have largely been focused on network expansion for increased nationwide coverage. Telkom Kenya has seen many different changes in its operations, structure and workforce. The changes which have taken place at Telkom Kenya Ltd. include downsizing, acquisition, structural changes, strategic changes and restructuring among others. These have been managed through use of consultants, change planning, communication and buy in. The company has changed its organization structure, its strategic focus, its employee size and composition and also its management orientation. The changes have been brought about by competition, market liberalization, technological advancements and changing customer demands. The challenges in implementing changes at Telkom Kenya include lack of a clear cut plan in managing the retrenchment, limited resources to finance the downsizing, resistance to change by employees and the dynamism of the telecommunication industry.

\section{Problem Statement}

Organizations are often faced with continuous changes that require different approaches to implement and manage the necessary processes in the organization. Ansoff and Nakamura, (2013) assert that organizations' operating environments are characterised by ever increasing customers' demands and expectations, shrinking product life cycles, changes in technology and the never-ending search for efficiency that is demanded from organization's managers and executives. Organizations therefore need to learn and adapt to these changes not only by adopting the relevant strategic plans but also by constantly revisiting services and product offering as well as realigning organization's overall strategy, process and structure. Telkom Kenya has seen many different changes in its operations, structure and workforce. The company has also seen its ownership structure change over the years with government reducing its shareholding to a great extent. The planning processes the company has adopted to implement these changes is the focus of this study. This study therefore sought to establish whether strategic planning has any relationship with change management.

\section{Research Objective}

The study's main objective was to determine how strategic planning affects change management in telecommunication industry in Kenya with specific reference to Telkom Kenya Limited. 


\section{Theoretical Literature Review}

\section{LITERATURE REVIEW}

The study was guided by Contingency Planning theory of change management. This theory was developed from the works of Woodward (1958). Contingency planning is also referred to as business continuity planning. The theory's association with change management threat is on the basics that all business risk cannot be fully eliminated in practice. With reference to this study, contingency theory can be used to mean controls, plans, process and the totality of activities. It is the act of preparing for major catastrophe and occurrences, articulating malleable strategies and rationalizing appropriate assets that will come into play in the event (James, 2013). In this study contingency planning theory involves the preparing for the unexpected and planning for the unknown. The basic purpose of contingency planning theory is to minimize the adverse consequences of catastrophe and occurrences (James, 2013). Contingency Planning Theory was adopted in this study because it describes and explains how change in technological advancement, social values, and regulations can affect decisions regarding implementation process. The theory thus supports study objective on strategic planning

\section{Empirical Literature Review \\ Strategic Planning and Change Management}

Eriksson and Fundin (2018) investigated the role of visual management for a dynamic strategic change. According to the study, strategic changes in an organization will face challenges not only related to the changes as such, but also with regard to how the vision of the future is interpreted and understood by the organization. The underlying study objective was to problematize episodic change processes with regard to communication and to contribute with a proposed model on how to facilitate dynamic strategic change management using visual management. The study used interdisciplinary approach by linking change management literature to visual communication to be used in visual management. The findings of the study show that a proposed model that presents a vibrant intermittent change process can be managed in terms of visual management, potential pitfalls to avoid, and what ambidextrous capabilities are needed throughout the complete episodic change Eriksson \& Fundin, (2018).

The implication for the study is that it dopts implemetation of Kotter's (2009) eight steps on how to strategically manage change in combination with theories on irregular change as suggested. The emergent model of change was as a response to criticism leveled against the planned model of change. The model is also refered to as continous improvement and also organizational learning Burnes (2011). Kotters model views change as as a continuous and open-ended process of adaption to changing condtions and circumstances. The model suggests that for rapid change, it is impossible for change initiators to effectively plan, identify and implement changes that are necessary in the organization. Consequently the responsibility for organisational change has to become increasingly devolved. The model stresses that change should not be perceived as a series of linear events within a given duration of time but rather it is continuous, open-ended process of adaptation to changing conditions and circumstanes Eriksson \& Fundin, (2018).

Vantrappen and Wirtz, (2018) also examined the smarter process for managing and explaining organization design change. According to the authors, organizations change their structures continually and during the process of change in organization strategy, employees understand why it happens. Never the less, change management occurs much more frequently than strategy changes. Vantrappen and Wirtz (2018) draws on their long advisory experience to propose three premises about organization stategic planning. They decribe the implications of the premises for managers who need to make and explain organization design changes. 
The study established on premise one that there is no one size fits all organizations in all circumstances. The second premise is that there are usually good reasons why companies are the way they are, which implies that organizations need to consider a gradual approach as the default, possibly on the basis of casual loops. The third premise is that an organization is more than just structure. The implications are that simple minded changes should include process, technology, culture and people as described by various frameworks.

\section{Research Hypothesis}

The study had one hypothesis to test the relationship between the two variables.

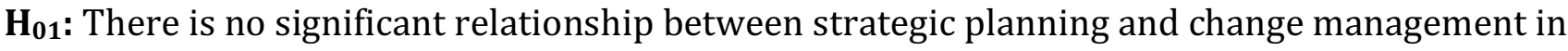
Telkom Kenya Ltd.

\section{Conceptual Framework}

A conceptual framework presents and defines the relationship between the study variables. The independent variable was the Strategic Planning while the dependent variable was Change Management as depicted in Figure 1.

Figure 1: Conceptual model

Independent Variable

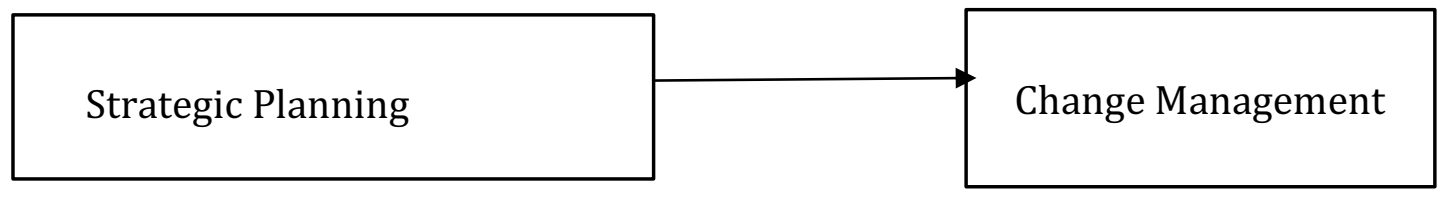

Dependent Variable

\section{RESEARCH METHODOLOGY}

This research adopted a descriptive design to obtain the most relevant, recent and in-depth information on the study topic. The target population was 1450 employees of Telkom Kenya comprised of senior level management, middle level management and non- management staff at the Head office in Nairobi. Kombo and Tromp (2009) indicated that a sample size of $10 \%$ or $20 \%$ of the target population selected using stratified sampling is adequate to generalize the study findings. In this context, the study used $10 \%$ of the population which is the minimum recommended.

This study adopted questionnaire as the main data collection tool. According to Orodho (2009), questionnaire measures likelihood of straight, even and blunt answers. This can be superior to an interview because social communion operates strongly in a face of situation that may prevent the person from expressing what he feels to be socially or professionally unacceptable views. The questionnaire contained closed-ended questions using Linkert scaled questions where 1 = strongly disagree, $2=$ disagree, $3=$ uncertain, $4=$ agree and $5=$ strongly agree.

A pilot study was conducted before questionnaires were distributed for data collection. The pilot study was conducted at Telkom Thika branch, where the targeted number of employees was fifteen (15). This branch was not included in the final data collection to avoid bias. The purpose of pre-testing the research instrument was to verify whether the questionnaires were clear to the respondents and establish whether the feedback form would effectively address 
the data needed for the study. The pilot was therefore a good test for validity of the research instrument.

\section{Reliability Tests}

The study used alpha co-efficient of 0.7 or above for all constructs that were considered adequate for the study. The construct multiple of reliability is Cronbach Alpha. According to Kombo and Tromp (2009) the standard acceptable reliability coefficient is 0.7. The study adopted Cronbach Alpha and used it to test research instruments reliability. The pilot study also tested the reliability of the questionnaire in which the questionnaires were pre-tested to a sample group similar to the actual sample.

The data collected in the main study was coded and grouped then tabulated. Descriptive analysis and linear regression analysis were used to analyse the data. Central tendency measures including mean and standard deviation were used to examine individual variables while correlation and regression coefficients were used to establish relationship between strategic planning and the resultant change management. The open ended questions were analysed using conceptual content analysis to generate statistics.

The regression models used were of the form:

Where:

$$
Y=\beta_{0}+\beta_{1} X_{1}+\varepsilon
$$

$\mathrm{Y}=$ Change Management;

$\beta_{0}=$ Regression constant;

$\beta_{1}=$ Coefficients of strategic planning;

$\mathrm{X}_{1}=$ Strategic Planning and

$\varepsilon=$ error term.

The findings were presented in terms of percentages, tables and charts. Ethical considerations were observed based on moral standards. Furthermore respondents' consents were obtained prior to collecting the data. A research permit to carry out the study was also obtained from the National Commission of Science Technology and Innovation (NACOSTI), the body charged with regulation of research in Kenya.

\section{RESULTS OF THE STUDY}

At the end of the data collection, a total of 118 questionnaires had been fully filled and returned out of the 145 that were issued showing an impressive $81 \%$ response rate. A demographic analysis of the responses showed that $59 \%$ of the respondents were male and $41 \%$ were female. Analysis by age showed that the majority (36\%) of the respondents indicated they were aged between 31years and 35years, followed by respondents whose ages fell between 26 years and 30 years at 23\%, respondents aged 25 years and below were 19\% while the respondents aged between 36 years and 40 years were $12 \%$ and finally those over 41 years were $10 \%$. Analysis was also done by level of education and the results showed that the majority of the respondents had attained a diploma at 33\% followed by bachelor's degree at $25 \%$, and finally post-graduate education at 15\%. Respondents who indicated any other level of education were at $19 \%$ while $1 \%$ had PhDs. None indicated having primary school education but $7 \%$ had secondary school education. This implies that respondents' education level was adequate to enable them interpret and answer the research questions.

Further analysis showed that majority (48\%) of the respondents had worked in the company for between 4 and 7 years, followed by 8 to 12 years at 34\%, 3 years and below at 19\% while 
9\% of the respondents indicated above 13 years. This shows that respondents had a good understanding of the organization given their longevity in the organization and hence were in a good position to provide relevant answers to study questions.

\section{Descriptive Statistics}

The study's objective was to examine and determine how strategic planning affects change management at Telkom Kenya Ltd. Data on the study's variables were collected by requiring the respondents to use a five-point Likert scale. A set of six questions were used to determine how strategic planning affects change management and the results are shown in Table 1.

Table 1 Descriptive Statistics

\begin{tabular}{|l|l|l|}
\hline Variable & Mean & Std. Deviation \\
\hline Strategic Planning & 3.72 & 1.0752 \\
\hline Change Management & 3.64 & 1.0506 \\
\hline
\end{tabular}

As shown in Table 1, the mean for strategic planning was 3.72 which is above the mid-point value of 2.5. This implies that the respondents perceived strategic planning to be important in the organization. The standard deviation had a low value (1.0752) which shows a low diversity in opinions about strategic planning in the organization. Regarding change management, the mean value was 3.64 which is also above the mid-point of 2.5 while the standard deviation was 1.0506. These values indicate that the respondents perceived change management to be important, an opinion which was consistent among majority of the respondents.

Correlation was tested using Pearson correlation analysis to establish the association between strategic planning and change management. The results are presented in Table 2.

Table 2: Correlation between Strategic Planning and Change Management

\begin{tabular}{llc}
\hline & & Change Management \\
\hline & Pearson of Correlation & $0.658^{* *}$ \\
Strategic Planning styles & Sig. (2-tailed) & 0.000 \\
& $\mathrm{n}$ & 118 \\
& \\
\hline$*$ Correlation is significant at the level of 0.01 level (2-tailed) & \\
\hline
\end{tabular}

As is evident in Table 2, there is a moderate positive correlation between Strategic Planning and Change Management $(\mathrm{r}=0.658, \mathrm{p} \leq 0.01)$. This implies that as strategic planning varies, change management also varies in the same direction such that a unit change in strategic planning results in $65.8 \%$ variation in change management.

\section{Hypothesis Testing}

The study hypothesized that there was a positive relationship between strategic planning and change management. The study used linear regression analysis to test this hypothesis. These tests were done in SPSS version 24 at 95\% confidence interval. The results are presented in Table 3.

Table 3: Model Summary Strategic Planning

\begin{tabular}{|c|c|c|c|c|c|c|c|c|c|}
\hline Model & $\mathbf{R}$ & $\begin{array}{c}\mathbf{R} \\
\text { Square }\end{array}$ & $\begin{array}{l}\text { Adjusted R } \\
\text { Square }\end{array}$ & $\begin{array}{l}\text { Std. Error } \\
\text { of the } \\
\text { estimate }\end{array}$ & $\begin{array}{l}\mathrm{R} \\
\text { Square } \\
\text { Change }\end{array}$ & $\begin{array}{c}F \\
\text { Change }\end{array}$ & df1 & df2 & Sig. F \\
\hline 1 & $.658^{\mathrm{a}}$ & .570 & .464 & .52831 & $.570^{\circ}$ & 73.571 & 1 & 88 & .000 \\
\hline
\end{tabular}


The results in Table 3 show that the relationship between strategic planning and change management was moderate and positive $\left(\mathrm{R}^{2}=0.57\right)$. This implies that this model can be used to explain $57 \%$ of the variations in change management.

Further testing of the model was done using analysis of variance (ANOVA) at 95\% confidence level and the results are as shown in Table 4.

Table 4: ANOVA and Coefficients of strategic planning

\begin{tabular}{|c|c|c|c|c|c|c|}
\hline Model & & $\begin{array}{c}\text { Sam of } \\
\text { Squares }\end{array}$ & df & $\begin{array}{c}\text { Mean } \\
\text { square }\end{array}$ & f & Sig. \\
\hline & Regression & 20.584 & 1 & 20.584 & 73.571 & $.000^{\mathrm{b}}$ \\
\hline & Residual & 23.223 & 88 & & & \\
\hline & Total & 43.807 & 89 & & & \\
\hline
\end{tabular}

a. Dependent Variable is Change Management

b. Strategic Planning

As can be seen from Table 4, ANOVA the variance between strategic planning and change management is significant $(\mathrm{p} \leq 0.000)$ and the $\mathrm{F}$-critical was large $(\mathrm{F}=62.251)$. This indicates that mean variance between the independent and the dependent variable is strong.

Regression analysis was last performed to determine whether strategic planning is related to change management. The results are presented in Table 5.

Table 5 Regression of Coefficients

\begin{tabular}{|c|c|c|c|c|c|c|}
\hline \multirow{2}{*}{\multicolumn{2}{|c|}{ Model }} & \multicolumn{2}{|c|}{$\begin{array}{c}\text { Unstandardized } \\
\text { Coefficients }\end{array}$} & \multicolumn{3}{|l|}{$\begin{array}{c}\text { Standardized } \\
\text { Coefficients }\end{array}$} \\
\hline & & B & Std. error & Beta & $\mathrm{T}$ & Sig \\
\hline \multirow[t]{2}{*}{1} & Constant & 1.0752 & .352 & & 3.449 & 0.000 \\
\hline & Strategic Planning & 0.735 & 0.83 & 0.685 & 3.578 & 0.000 \\
\hline
\end{tabular}

As Table 5 indicates, strategic planning had a positive and large regression coefficient $(\beta=0.735)$ which is statistically significant $(p \leq 0.000)$. This indicates that there is a strong and positive relationship between strategic planning and change management such that a unit change of strategic planning leads to $73.5 \%$ variation in change management. Using the equation $Y=\beta_{0}+\beta_{1} X_{1}+\varepsilon$, this relationship may be modelled mathematically as:

$$
Y=1.915+0.570 X_{1}+0.548
$$

Where:

$\mathrm{Y}$ is the Change Management;

$\beta_{0}$ is the regression constant;

$\beta_{1}$ is the coefficients of strategic planning

$\mathrm{X}_{1}$ is the strategic planning and

$\varepsilon$ is the error term.

\section{RESULTS AND DISCUSSION}

The objective of this study was to establish the relationship between strategic planning and change management in Telecommunications industry in Kenya. One hypothesis $\left(\mathrm{H}_{01}\right)$ which stated that there is no significant relationship between strategic planning and change management in Telkom Kenya Ltd was used to investigate this relationship. The hypothesis was tested using regression analysis. The results in Table 5 show that the R-Square is 0.658 and $\mathrm{p}$-value is $0.01<0.05$. This confirms that model can be used to determine $65.8 \%$ of the variations in the relationship between strategic planning and change management. This 
indicates that the null hypothesis is rejected which means that strategic planning affects change management. The study findings are in agreement with other scholars' findings such as Burnes (2011. The study findings are also in agreement with other scholar's findings such as Eriksson and Fundin (2018) whose findings show that a proposed model that presents a vibrant intermittent change process can be managed in terms of visual management, potential pitfalls to avoid, and what ambidextrous capabilities are needed throughout the complete episodic change.

These results have confirmed the researchers' proposition that strategic planning has a relationship with change management. In many organizations, change management process is disconnected from strategic planning process. Thus strategic planning is merely done as a routine activity that is not tied to change management. Such organizations tend loose out when implementing changes. It is therefore pertinent that change management should be undertaken only after various relevant strategies are identified which can then provide direction for implementing the desired changes.

\section{SUMMARY AND CONCLUSION}

The study's objective was to examine and determine whether strategic planning is related to change management at Telkom Kenya Ltd. The results reveal that strategic planning has a positive and significant relationship with change management. Based on the findings, the study concluded that strategic planning has a significant and positive relationship with change management. The study therefore concludes that changes in the strategic planning could lead to a variation on the change management at Telkom Kenya. Strategic planning is therefore an important factor which should be considered and undertaken whenever changes are being introduced in the organization.

\section{RECOMMENDATIONS}

Strategic planning involves, identifying the firm's mission and objectives, developing long term objectives and short-term operational plans, plan preparation, application and actual evaluation and control of the implementation process. Therefore, the study recommends that management of Telkom Kenya should embrace proper strategic planning during and before organization change process.

From the findings, the study recommended that Telkom Kenya Management and Board of Directors should strive to build a value system that puts strategic planning at the center of all its operations and ambitions for growth in their market as strategic planning is indeed their lifeline in the competitive telecommunication industry of Kenya. Other organizations too, such as Telkom Kenya, should have regular trainings on planning and find ways to endear junior managers to planning as a way of getting through their lives in the company. The study also recommended that similar studies be done in different contexts given the dynamic and competitive nature of the environment in Kenya in which telecommunication companies such as Telkom Kenya Ltd operate. This will help them establish whether the strategies they adopt can lead to their effective management of change.

\section{References}

Ansoff, H. I., \& Nakamura, G. I. (2013). Strategic Management. New york: Palgrave Macmillian.

Atikiya, R., \& Nzulwa, J. (2014). Factors Contributing to Successful Organizational Transformation at Kenya Wildlife Service. Asian Journal of Humanities and Social Sciences Volume 2 Issue 2, May, 10-18.

Burnes, B., \& Jackson, P. (2011). Success and Failure in Change management Management: An exploration of the role of values . Journal of change management vol. 11 (2), 133-162. 
Eriksson, Y., \& Fundin, A. (2018). Visual management for a dynamic strategic change. Journal of Change management Management Vol. 31 Issue 3, 712-727.

Hameri, A., \& Hintsa, A. (2014). Assessing the driver of change for cross border supply chain. International Journal of Physical Distribution and Logistics Management volume 39 issue 9, 741- 769.

Kumar, H. (2014). The Importance of Strategic Management Process in the Knowledge-Based Economy. Review of International Comparative Management. Vol 10 issue 1, 125 -133.

Mintzberg, H., Lample, J. B., Quinn, J., \& Ghoshal, S. (2002). The Strategy process: Concepts, context and cases . London: Prentice Hall.

Perreault, W., McCarthy, J. E., \& Canon, J. P. (2010). Basic Marketing: A Marketing Strategy planning approach . London : McGraw Hill.

Kombo, D., \& Tromp, D. (2009). Project and Thesis Writing: An introduction . Nairobi: Pauline Publishers .

Kothari, C. R. (2009). Research Methodology. New Delhi: New Age International. 